\title{
Synthesis, Discovery, and Quantitation of Dihomo-Isofurans: Biomarkers for In Vivo Adrenic Acid Peroxidation***
}

\author{
Aurélien de La Torre, Yiu Yiu Lee, Camille Oger, Per Torp Sangild, Thierry Durand, \\ Jetty Chung-Yung Lee,* and Jean-Marie Galano*
}

\begin{abstract}
The growing importance of lipidomics, and the interest of non-enzymatic metabolites of polyunsaturated fatty acids (PUFAs) prompted us to initiate the synthesis of novel dihomo-IsoF compounds. Such metabolites of adrenic acid, the main PUFA in white matter, were synthesized using a divergent approach based on an orthoester cyclization. LC-MS/MS investigation on pig brains showed the potential of this novel biomarker for the first time, as a powerful new tool for brain lipid peroxidation assessment.
\end{abstract}

$\mathrm{O}_{\mathrm{x}}$ ygenated metabolites of polyunsaturated fatty acids (PUFAs) are key classes of natural products generated by living organisms. The levels are regulated by the presence of reactive oxygen species (ROS). Among them, isoprostanes (IsoPs), liberated through lipid peroxidation of arachidonic acid (AA), and more recently neuroprostanes (NeuroPs), from docosahexaenoic acid (DHA), are widely studied. ${ }^{[1,2]}$ IsoPs are used as systemic oxidative stress biomarkers in vivo whereas NeuroPs are specific for neurodegenerative diseases. $^{[3]}$ A novel peroxidation pathway of PUFAs was discovered and it generates tetrahydrofuran (THF) derivatives, that is, isofurans (IsoFs) from $\mathrm{AA}^{[4]}$ and neurofurans (NeuroFs) from DHA. ${ }^{[5]}$ These compounds could be highly valuable biomarkers of oxidative stress because they appear to be more abundantly produced than their isoprostanoid counterparts, and because their formation is dependent upon oxygen tension. We previously showed that $\mathrm{F}_{2}$-dihomo-IsoPs, isoprostanoid metabolites of adrenic acid (AdA, being the most important PUFA in white matter) ${ }^{[6]}$ and $7-$ and $17-\mathrm{F}_{2 \mathrm{t}^{-}}$ dihomo-IsoPs are biomarkers for the early detection of Rett syndrome (RTT), and subsequently, oxidative damage of the

[*] A. de La Torre, Dr. C. Oger, Dr. T. Durand, Dr. J.-M. Galano Institut des Biomolécules Max Mousseron (IBMM) UMR CNRS 5247-Universités de Montpellier I et II, ENSCM, Faculté de Pharmacie

15 Av. Charles Flahault, 34093 Montpellier cedex 05 (France) E-mail: jean-marie.galano@univ-montp1.fr

Dr. J. C. Y. Lee

School of Biological Sciences, The University of Hong Kong Pokfulam Road, Hong Kong SAR (China)

E-mail: jettylee@hku.hk

P. T. Sangild

Department of Nutrition, Exercise and Sports, Faculty of Science University of Copenhagen, Frederiksberg (Denmark)

[**] We thank the Université de Montpellier I (BQR 2011), CNRS and the Fondation pour la Recherche Médicale for financial support, and Dr. Martin Christlieb and Prof. Ullrich Jahn for their technical advice.
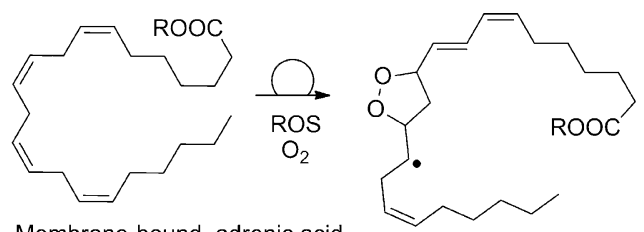

Membrane-bound adrenic acid

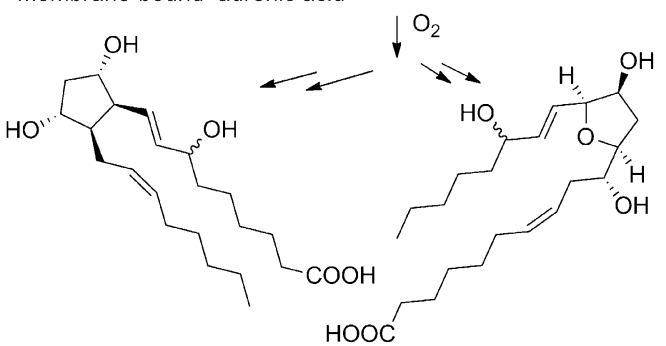

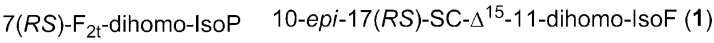

Scheme 1. Representative structures of dihomo-IsoP and dihomo-IsoF from AdA peroxidation. $\mathrm{ROS}=$ reactive oxygen species, $\mathrm{R}=$ phosphate group.

myelin (Scheme 1). ${ }^{[7]}$ It is therefore reasonable to assume that IsoF metabolites of AdA, namely dihomo-IsoFs, do exist and could be complementary biomarkers of RTT and other neuronal damage. In pursuing this hypothesis, the first synthesis of dihomo-IsoFs is described herein. For the first time, concentrations of dihomo-IsoFs were determined by LC-MS/MS to confirm their presence in vivo, particularly in the brain, and to compare them with those of known biomarkers of oxidative stress, mainly IsoPs, NeuroPs ${ }^{[8]}$ and $\mathrm{F}_{2}$-dihomo-IsoPs.

The biosynthesis of dihomo-IsoFs can theoretically give 32 possible diastereoisomers, and because two biosynthesis pathways coexist two classes of four families are present, that is, the alkenyl-IsoFs and enediol-IsoFs. ${ }^{[9]}$ Therefore, a total of 256 isomers are potentially generated in vivo.

Three different synthetic strategies have been reported for IsoFs and NeuroFs over the past decade by the groups of Falck, Taber, and Zanoni-Vidari. ${ }^{[10-14]}$ To identify more distinct and relevant metabolites for biological investigation, we developed a versatile strategy based on a novel framework for both alkenyl- and enediol-dihomo-IsoFs.

Retrosynthetic analysis of alkenyl-dihomo-IsoFs enabled us to identify the THF precursors A (Scheme 2). To develop a common scaffold for both alkenyl- and enediol-isofuranoids, the polyalcohol derivative $\mathbf{C}$ would be a suitable target. Two cyclization processes (5-exo-tet for alkenyl and 5-endotet for enediol) could be foreseen with a suitably monoprotected orthoester derivative (B for alkenyl-type) following 


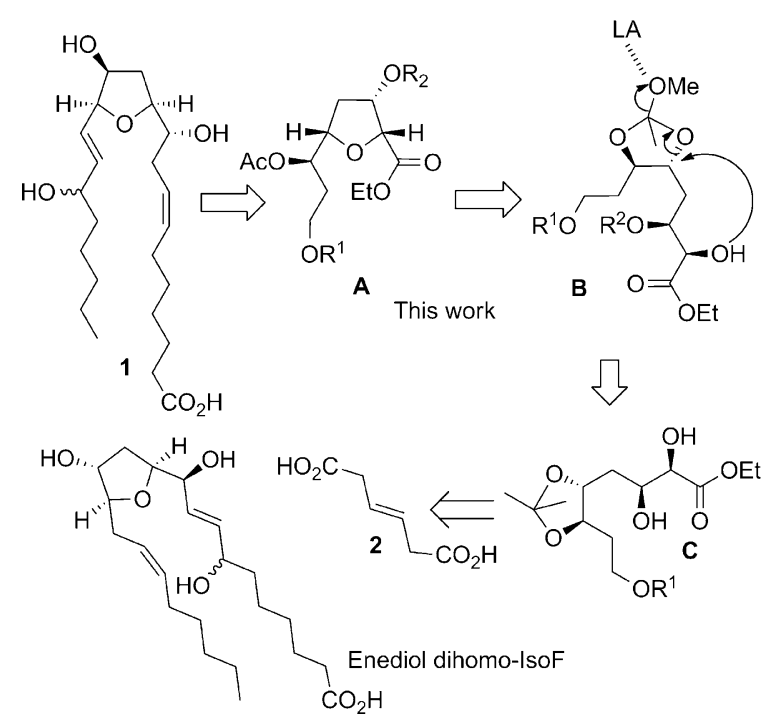

Scheme 2. Retrosynthetic analysis of alkyl-dihomo-IsoF derivatives. $\mathrm{LA}=$ Lewis acid.

the use of Borhan's stereoselective orthoester cyclization of 1,2,n-triols. ${ }^{[15]}$ The compound $\mathbf{C}$ should be available from trans- $\beta$-muconic acid (2). Following this analysis we now describe the first synthesis of 10 -epi-17(RS)-SC- $\Delta^{15}-11$ dihomo-IsoF (1).

The synthesis started with a four-step sequence to access to the 1,6-diol 4 in $62 \%$ yield and in virtually optically pure form (ee $>99 \%$; Scheme 3$) \cdot{ }^{[16]}$ Esterification of 2 with acetyl chloride in an anhydrous $i \mathrm{PrOH}$ solution and subsequent
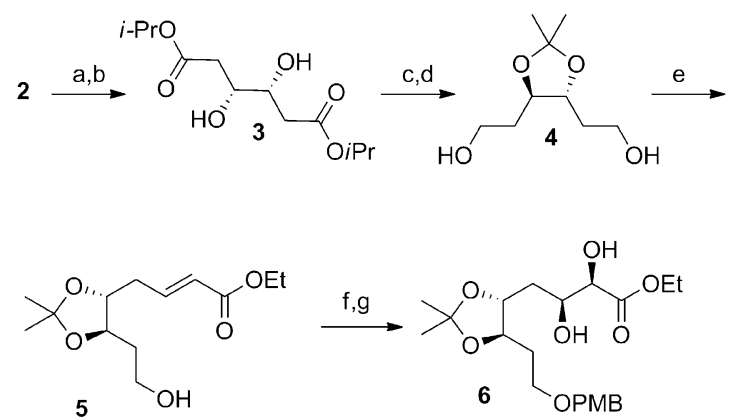

Scheme 3. Reagents and conditions: a) $\mathrm{AcCl}, \mathrm{PrOH}, 100^{\circ} \mathrm{C}, 89 \%$; b) AD-mix $\beta, \mathrm{MeSO}_{2} \mathrm{NH}_{2}, \mathrm{NaHCO}_{3}, t \mathrm{BuOH} / \mathrm{H}_{2} \mathrm{O}(1: 1), 0^{\circ} \mathrm{C}, 77 \%$; c) PTSA, 2,2-dimethoxypropane, RT, 99\%; d) $\mathrm{LiAlH}_{4}, \mathrm{THF}, 0^{\circ} \mathrm{C} \rightarrow \mathrm{RT}$, $91 \%$; e) $\mathrm{MnO}_{2}, \mathrm{Ph}_{3} \mathrm{PCHCO}_{2} \mathrm{Et}, 1,2$-dichloroethane, $62{ }^{\circ} \mathrm{C}, 62 \%$; f) PMBTCA, La(OTf) $)_{3}$, toluene, RT, $93 \%$; g) AD-mix $\alpha, \mathrm{MeSO}_{2} \mathrm{NH}_{2}$, tBuOH $/ \mathrm{H}_{2} \mathrm{O}(1: 1), 0^{\circ} \mathrm{C}$ to $\mathrm{RT}, 94 \%$, d.r. $=88: 12$. $\mathrm{PMBTCA}=$ paramethoxybenzyl trichloroacetimidate, PTSA = para-toluenesulfonic acid, $\mathrm{Tf}=$ trifluoromethanesulfonyl.

Sharpless asymmetric dihydroxylation gave the corresponding diol 3. Acetonide protection and ester reduction with $\mathrm{LiAlH}_{4}$ gave 4 on large scale $(15 \mathrm{~g})$. This $\mathrm{C}_{2}$-symmetric structure was then selectively mono-oxidized and elongated by a Wittig reaction in the same pot, ${ }^{[17]}$ thereby resulting in the $\alpha, \beta$-unsaturated ester 5 in $62 \%$ yield. Protection of the remaining free alcohol yielded the corresponding PMB ether prior to another Sharpless asymmetric dihydroxylation, thus affording the diol $\mathbf{6}$ in good yield and good diastereoselectivity (d.r. $=88: 12$ ).

Regioselective monoprotection of $\mathbf{6}$ was achieved using Kusumoto's method through orthoester hydrolysis. ${ }^{[18]}$ Treatment of $\mathbf{6}$ with trimethyl orthoacetate and PTSA resulted in placing the acyl group in the $\beta$-position (4:1). However, subsequent acidic cleavage of the acetonide with PTSA caused a migration of the acyl moiety to the liberated 1,2-diol. Nevertheless, monoprotection was achieved by using trimethyl orthobenzoate to introduce the benzoyl group to the $\beta$-position of $\mathbf{7}$, which was isolated in addition to 8 with a $4: 1$ regioselectivity (Scheme 4). Interestingly, the benzoyl group
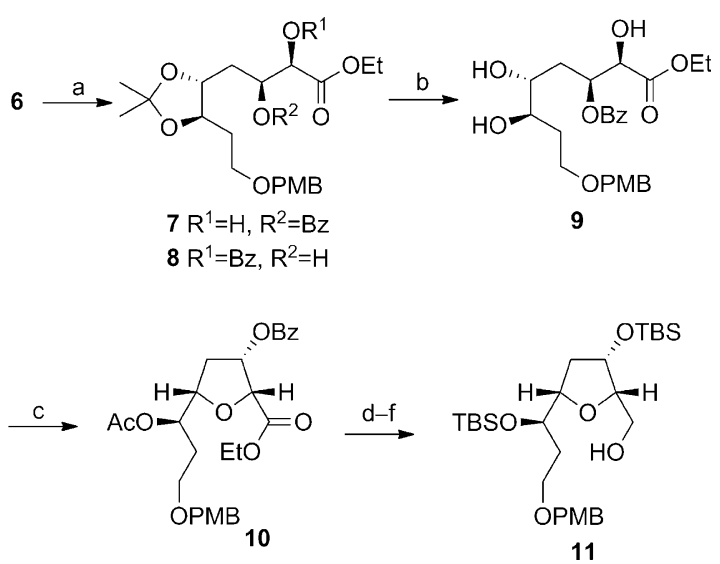

Scheme 4. Reagents and conditions: a) $\mathrm{PhC}(\mathrm{OMe})_{3}, \mathrm{PTSA}, \mathrm{CH}_{2} \mathrm{Cl}_{2}, \mathrm{RT}$; then PTSA, $\mathrm{H}_{2} \mathrm{O}, \mathrm{RT}, 88 \%$ as a $(4: 1)$ mixture of 7 and 8 ; b) PTSA, $\mathrm{MeOH} / \mathrm{H}_{2} \mathrm{O}(9: 1)$, RT, then $\mathrm{NaHCO}_{3}(\mathrm{~s}), 66 \%$; c) $\mathrm{MeC}(\mathrm{OMe})_{3}, \mathrm{PPTS}$, $\mathrm{CH}_{2} \mathrm{Cl}_{2}$, RT; then $\mathrm{BF}_{3} . \mathrm{Et}_{2} \mathrm{O}, 15^{\circ} \mathrm{C}, 60 \%$; d) $\mathrm{K}_{2} \mathrm{CO}_{3}, \mathrm{MeOH}, \mathrm{RT}, 72 \%$; e) TBSCl, imidazole, DMAP, $\mathrm{CH}_{2} \mathrm{Cl}_{2}, \mathrm{RT}$, quant; f) $\mathrm{LiBH}_{4}, \mathrm{MeOH}, \mathrm{THF}$, $86^{\circ} \mathrm{C}, 86 \%$. DMAP $=4$ - $(N, N$-dimethylamino $)$ pyridine, $\mathrm{PPTS}=$ pyridinium para-toluenesulfonate, TBS $=$ tert-butyldimethylsilyl.

did not migrate from the $\beta$-position under acidic conditions, but did migrate from the $\alpha$ - to the $\beta$-position under basic conditions. Thus, the mixture of regioisomers $\mathbf{7}$ and $\mathbf{8}$ was directly treated with PTSA in $\mathrm{MeOH} / \mathrm{H}_{2} \mathrm{O}$ (9:1), followed by a basic quench with solid $\mathrm{NaHCO}_{3}$ to afford the triol 9 as a single regioisomer. The triol $\mathbf{9}$ was then treated under reaction conditions developed by the group of Borhan, ${ }^{[15]}$ that is, orthoester formation with $\mathrm{MeC}(\mathrm{OMe})_{3}$ and PPTS, followed by in situ addition of catalytic $\mathrm{BF}_{3} \cdot \mathrm{Et}_{2} \mathrm{O}$ to conduct the intramolecular attack at the orthoester intermediate. The cyclization process was extremely temperature dependent. Lewis acid addition at $30^{\circ} \mathrm{C}$ led to consecutive cleavage of the PMB group, whereas running it at $0^{\circ} \mathrm{C}$ prevented cyclization and deprotection. Best results were obtained at $15^{\circ} \mathrm{C}$, thus yielding the THF derivative $\mathbf{1 0}$ in $60 \%$ yield. The relative configuration of $\mathbf{1 0}$ was confirmed by NOESY NMR. At the stage of the synthesis and after purification by flash chromatography, $\mathbf{1 0}$ appears to be free of the minor diastereoisomer observed when $\mathbf{6}$ was isolated. The Ac and $\mathrm{Bz}$ protecting groups of $\mathbf{1 0}$ were subsequently transformed into TBS groups by methanolysis with $\mathrm{K}_{2} \mathrm{CO}_{3}$ in $\mathrm{MeOH}$ followed by addition of TBSCl. Reduction of the methyl ester group with $\mathrm{LiBH}_{4}$ 
gave the compound $\mathbf{1 1}$ in $62 \%$ yield over three steps. This compound is the key intermediate for the generation of all alkenyl-IsoFs, alkenyl-dihomo-IsoFs, and alkenyl-NeuroFs.

The primary alcohol $\mathbf{1 1}$ was transformed into the corresponding aldehyde with the Dess-Martin periodinane and followed by a Horner-Wadsworth-Emmons reaction with the commercially available phosphonate $\mathbf{1 2}$ (Scheme 5). The
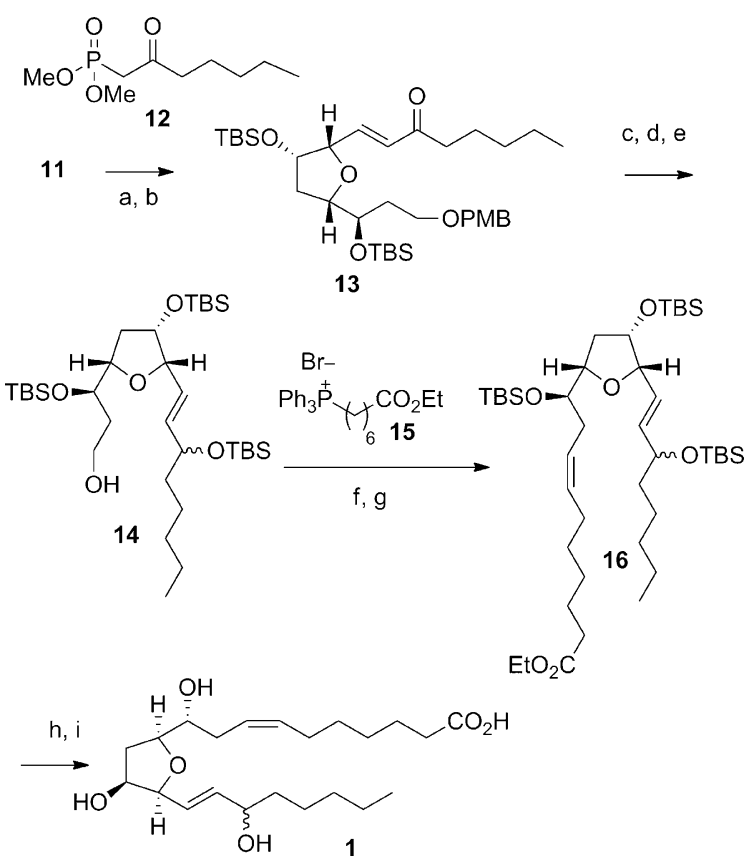

Scheme 5. Reagents and conditions: a) DMP, $\mathrm{CH}_{2} \mathrm{Cl}_{2}, \mathrm{RT}$; b) $\mathrm{Ba}(\mathrm{OH})_{2}$, 12, THF, RT, $60 \%$ over two steps; c) $\mathrm{CeCl}_{3} .7 \mathrm{H}_{2} \mathrm{O}, \mathrm{NaBH}_{4}, \mathrm{MeOH}, 0^{\circ} \mathrm{C}$; d) TBSCl, imidazole, DMAP, $\mathrm{CH}_{2} \mathrm{Cl}_{2}, \mathrm{RT}, 85 \%$ over two steps; e) DDQ, $\mathrm{CH}_{2} \mathrm{Cl}_{2} / \mathrm{H}_{2} \mathrm{O}$ (10:1), $0^{\circ} \mathrm{C}$ to RT, 80\%; f) DMP, $\mathrm{CH}_{2} \mathrm{Cl}_{2}, \mathrm{RT}$; g) 15, NaHMDS, THF, $-78^{\circ} \mathrm{C}$ to RT, $65 \%$ over two steps; h) TBAF, THF, RT; i) $\mathrm{LiOH}, \mathrm{THF} / \mathrm{H}_{2} \mathrm{O}(1: 1), \mathrm{RT}, 76 \%$ over two steps. DMP = Dess-Martin periodinane, $\mathrm{DDQ}=2$,3-dichloro-5,6-dicyano-1,4-benzoquinone, $\mathrm{NaHMDS}=$ sodium bis (trimethylsilyl) amide, TBAF = tetrabutylammonium fluoride.

enone $\mathbf{1 3}$ was obtained in $60 \%$ yield and thus further reduced under Luche's conditions and protected with a TBS group. Cleavage of the PMB group provided the primary alcohol 14 in $68 \%$ yield over three steps. Another oxidation/Wittig sequence with the phosphonium bromide $\mathbf{1 5}$ gave the ethyl ester $\mathbf{1 6}$ in $65 \%$ yield. Finally, exhaustive silyl ether deprotection and saponification of the ester group yielded 10-epi$17(R S)$-SC- $\Delta^{15}$-11-dihomo-IsoF (1) in $76 \%$ yield.

Brain tissue consumes approximately $20 \%$ of the total oxygen in the body. This consumption increases the likelihood of brain lipid peroxidation when injured because of the high abundance of PUFAs, especially AA, AdA, and DHA. The localization of PUFA in the brain is specific: DHA is enriched in grey matter and AdA is found in white matter, whereas AA and EPA are evenly distributed. These brain PUFAs are subject to lipid peroxidation (LPO) and oxidative damage within the central nervous system. Furthermore, the products released upon LPO may depend on the oxygen tension in the brain; a higher tension was reported in brain white matter compared to grey matter. ${ }^{[6,19]}$ The difference in PUFA localization and oxygen tension suggests the importance of measuring the appropriate LPO metabolites in the different parts of the brain. Lipids of the prefrontal cortex and medial prefrontal cortex of preterm pig (116 days) brains were extracted by Folch solution and subjected to alkaline hydrolysis. Thereafter, AA, DHA, and AdA and the LPO metabolites were purified by anionic solid-phase extraction and analyzed by LC-MS/MS. ${ }^{[20]}$ It was found, that the levels of DHA:AA:AdA amounted to approximately 1:5:0.1 in the prefrontal cortex and 1:2:0.07 in the medial prefrontal cortex. These levels represent the total PUFA concentration of the brain tissue without differentiating grey and white matter.

The determination of LPO metabolites revealed significantly high concentrations of $7(R S)-7-\mathrm{F}_{2 \mathrm{t}}$-dihomo-IsoP and $4(R S)-4-\mathrm{F}_{4 \mathrm{t}}-\mathrm{NeuroP}$ in the prefrontal cortex compared to $15-$ $\mathrm{F}_{2 \mathrm{t}}$-IsoP, 10- $\mathrm{F}_{4 \mathrm{t}}-\mathrm{NeuroP}$, or $17(R S)-17-\mathrm{F}_{2 \mathrm{t}}$-dihomo-IsoP (Figure $1 \mathrm{~A})$. Similarly, the levels of $4(R S)-4-\mathrm{F}_{4 \mathrm{t}}-\mathrm{NeuroP}$ and $7(R S)-7-\mathrm{F}_{2 \mathrm{t}}$-dihomo-IsoP were significantly higher in the medial prefrontal cortex compared to those of $5-\mathrm{F}_{2 \mathrm{t}}$-IsoP and $10-\mathrm{F}_{4 \mathrm{t}}-$ NeuroP (Figure $1 \mathrm{~B}$ ).

Interestingly, despite the relatively low concentration of AdA, 10-epi-17(RS)-SC- $\Delta^{15}$-11-dihomo-IsoF levels in both tissues were three- to fourfold higher than those of IsoFs and NeuroFs (Figures 1C and D). This difference is significant, since only up to 32 stereoisomers $\left(2^{5}\right)$ of the particular regioisomeric dihomo-IsoF series, represented by the standard $\mathbf{1}$, out of the 256 theoretical isomers were specifically measured, whereas IsoFs and NeuroFs levels represent the sum of all 256 and 512 potential metabolites, respectively.

The growth and development of the pig brain is similar to that of the human brain, therefore the results have a significant impact on the study of neuronal damage in humans. Primarily, our study revealed that 10 -epi-17(RS)-SC- $\Delta^{15}-11$ dihomo-IsoF levels were extraordinarily high compared to IsoFs and NeuroFs in the prefrontal cortex tissue of pig brains. Secondly, the dihomo-IsoF levels are comparable to those of $4(R S)-4-\mathrm{F}_{4 \mathrm{t}}-\mathrm{NeuroP}$ (Figure $1 \mathrm{~A}$ vs $\mathrm{C}$ ), which is to date the most prominent biomarker for oxidative stress related neuronal damage. ${ }^{[2,5]}$ These results show that the whole spectrum of isoprostanoid and isofuranoid metabolites represented by the novel 10 -epi-17(RS)-SC- $\Delta^{15}$-11-dihomoIsoF from AdA and known 4(RS)-4- $\mathrm{F}_{4 \mathrm{t}}-\mathrm{NeuroP}$ from DHA should be considered when evaluating neuronal damage and disease. Moreover, the isofuranoid AdA metabolite 1 has a much higher thermal and oxidative stability than 4(RS)-4$\mathrm{F}_{4 \mathrm{t}}$-NeuroP, and should lead to significantly more reliable and reproducible determination of LPO in brain tissues.

Importantly, the pig brain samples of the present study were at a homeostatic state. This state delineates the present results from those of a previous report, ${ }^{[21]}$ which found elevated IsoF levels at greater than $21 \%$ oxygen tension and elevated NeuroF at greater than $40 \%$ in the prefrontal cortex of piglets after resuscitation from hypoxaemia compared to nontreated controls.

A damaged prefrontal cortex is associated with cognitive dysfunction, bipolar disorder, and schizophrenia patients. ${ }^{[22,23]}$ This association parallels the recent finding of a relationship to oxidative stress, because the myelin fraction in neuronal 
A)

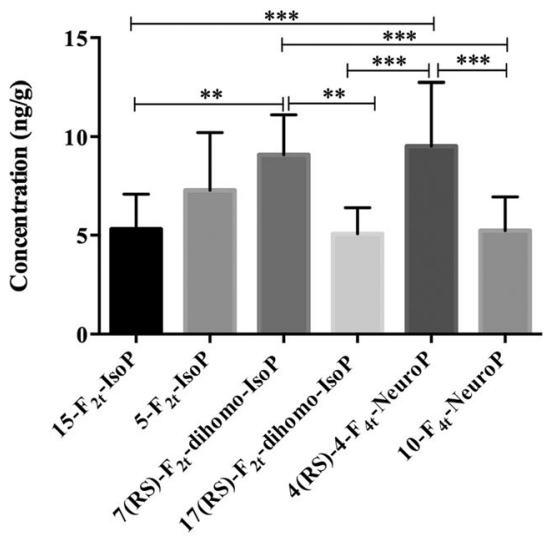

C)

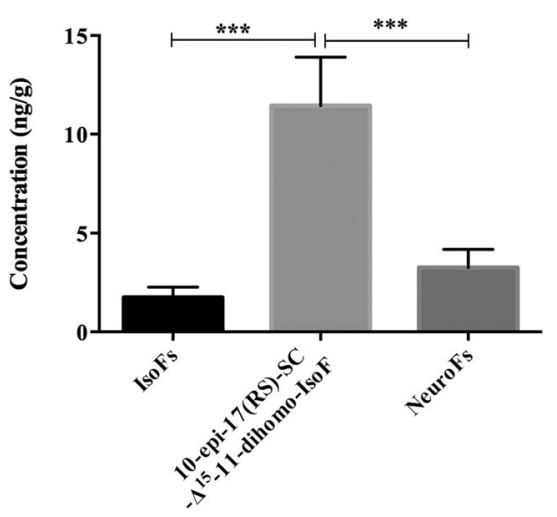

B)

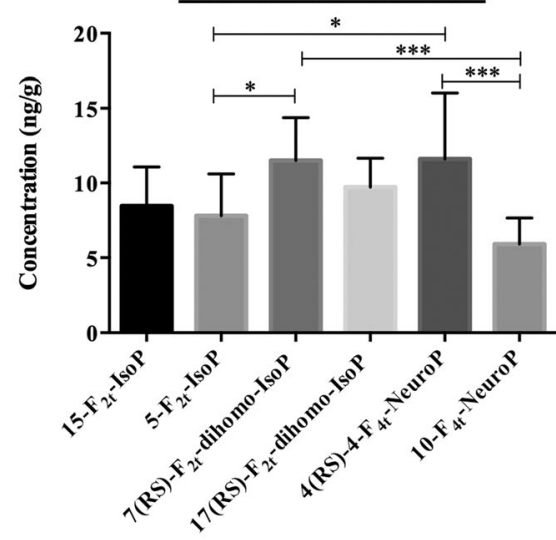

D)

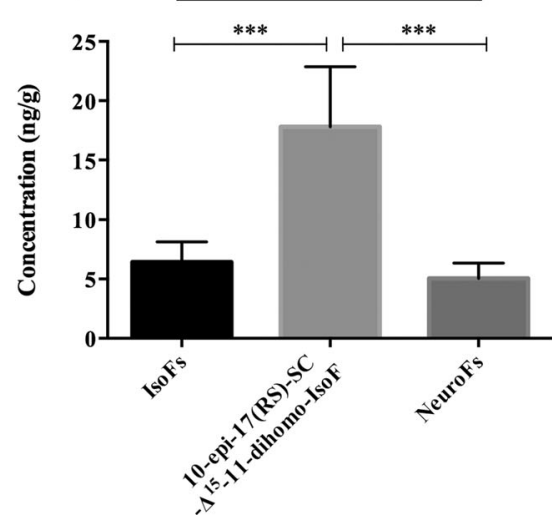

Figure 1. Concentration of isoprostanoids and isofuranaoids in pig brain tissues. Values are mean $\pm S D, n=12$. Concentration of each compound is expressed per $g$ tissue. Significant differences are annotated by $* p<0.05, * * p<0.01$, *** $* 0.001$.

cells from the prefrontal cortex of bipolar disorder patients had increased $\mathrm{F}_{2}$-IsoPs levels compared to controls. ${ }^{[23]}$

In conclusion, a flexible strategy allowed the total synthesis of both $\mathrm{C} 17$ epimers of 10-epi-SC- $\Delta^{15}$-11-dihomo-IsoF in 22 steps with a $1.5 \%$ overall yield. 10-epi-SC- $\Delta^{15}-11$ Dihomo-IsoF was discovered as a major metabolite of nonenzymatic free-radical-mediated peroxidation of AdA in the prefrontal and medial cortex of pig brain at homeostatic state. Thus, the new isofuranoid metabolite 10-epi-17(RS)SC- $\Delta^{15}$-11-dihomo-IsoF from AdA and known $4(R S)-4-\mathrm{F}_{4 \mathrm{t}^{-}}$ NeuroP from DHA should be considered as the leading complementary LPO biomarkers when evaluating neuronal damage and disease, whereby the new isofuran metabolite will have the advantage of considerably higher stability compared to NeuroP. Their quantification in the brain will likely provide beneficial insights into neurochemistry and shed light on intervention studies of neurobiology.
Keywords: biomarkers · lipids . mass spectrometry $\cdot$ oxidation . total synthesis

[1] J. D. Morrow, K. E. Hill, R. F. Burk, T. M. Nammour, K. F. Badr, L. J. Roberts, Proc. Natl. Acad. Sci. USA 1990,87, 9383 - 9387.

[2] L. J. Roberts II, T. J. Montine, W. R. Markesbery, A. R. Tapper, P. Hardy, S. Chemtob, W. D. Dettbarn, J. D. Morrow, J. Biol. Chem. 1998, 273, 13605-13612.

[3] U. Jahn, J.-M. Galano, T. Durand, Angew. Chem. 2008, 120, 5978-6041; Angew. Chem. Int. Ed. 2008, 47, 58945955.

[4] J. P. Fessel, N. A. Porter, K. P. Moore, J. R. Sheller, L. J. Roberts, Proc. Natl. Acad. Sci. USA 2002, 99, 16713-16718.

[5] W.-L. Song, J. A. Lawson, D. Reilly, J. Rokach, C.-T. Chang, B. Giasson, G. A. FitzGerald, J. Biol. Chem. 2008, 283, 616.

[6] E. R. Skinner, C. Watt, J. a. O. Besson, P. V. Best, Brain 1993, 116, 717-725.

[7] C. De Felice, C. Signorini, T. Durand, C. Oger, A. Guy, V. Bultel-Ponce, J.-M. Galano, L. Ciccoli, S. Leoncini, M. D'Esposito, S. Filosa, A. Pecorelli, G. Valacchi, J. Hayek, J. Lipid Res. 2011, 52, 2287-2297.

[8] C.-Y. J. Lee, R. C. S. Seet, S. H. Huang, L. H. Long, B. Halliwell, Antioxid. Redox Signaling 2009, 11, 407-420.

[9] D. F. Taber, J. P. Fessel, L. J. Roberts II, Prostaglandins Other Lipid Mediators 2004, 73, 47-50.

[10] J. R. Falck, L. Manmohan Reddy, K. Byun, W. B. Campbell, X.-Y. Yi, Bioorg. Med. Chem. Lett. 2007, 17, 2634-2638.

[11] D. F. Taber, P. Gu, R. Li, J. Org. Chem. 2009, 74, 5516-5522.

[12] D. F. Taber, Z. Zhang, J. Org. Chem. 2006, 71, 926-933.

[13] D. F. Taber, Y. Pan, X. Zhao, J. Org. Chem. 2004, 69, 7234-7240.

[14] M. Valli, P. Bruno, D. Sbarbada, A. Porta, G. Vidari, G. Zanoni, J. Org. Chem. 2013, 78, 5556-5567.

[15] T. Zheng, R. S. Narayan, J. M. Schomaker, B. Borhan, J. Am. Chem. Soc. 2005, 127, 6946-6947.

[16] B. H. Lipshutz, D. Buzard, C. Olsson, K. Noson, Tetrahedron 2004, 60, 4443-4449.

[17] D. J. Phillips, K. S. Pillinger, W. Li, A. E. Taylor, A. E. Graham, Tetrahedron 2007, 63, 10528-10533.

[18] M. Oikawa, A. Wada, F. Okazaki, S. Kusumoto, J. Org. Chem. 1996, 61, 4469-4471.

[19] Z.-C. Feng, E. L. Roberts Jr., T. J. Sick, M. Rosenthal, Brain Res. 1988, 445, 280-288.

[20] M. L. S. Chung, K. Y. E. Lee, C.-Y. J. Lee, Food Chem. Toxicol. 2013, 53, 205-213.

[21] R. Solberg, M. Longini, F. Proietti, P. Vezzosi, O. D. Saugstad, G. Buonocore, Free Radical Biol. Med. 2012, 53, 1061-1067.

[22] D. R. Euston, A. J. Gruber, B. L. McNaughton, Neuron 2012, 76, 1057-1070.

[23] A. C. Andreazza, J.-F. Wang, F. Salmasi, L. Shao, L. T. Young, J. Neurochem. 2013, 127, 552-561. 